
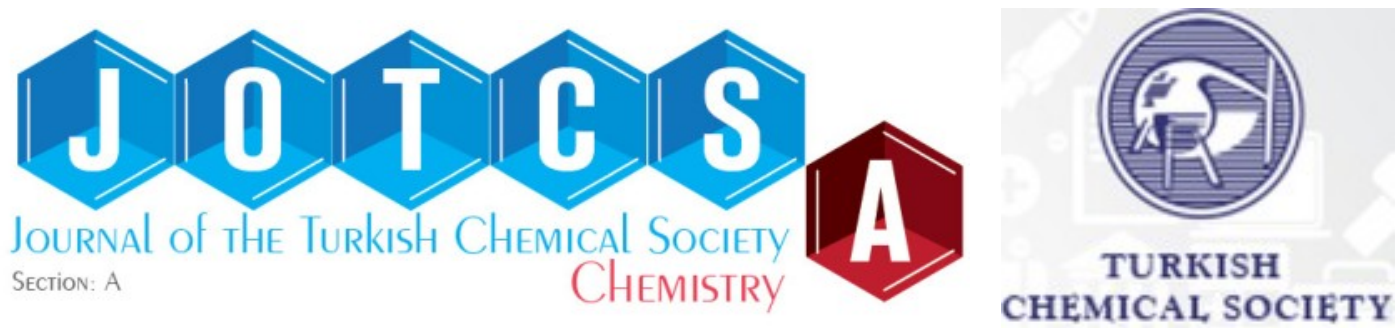

\title{
Characterization of a Bentonite and Its Permanent Aqueous Suspension
}

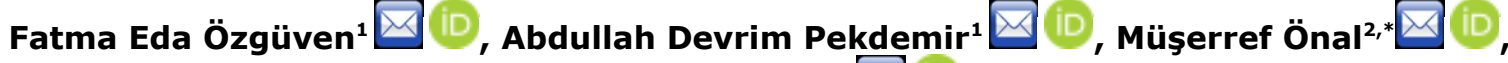 \\ Yüksel Sarıkayaª \\ ${ }^{1}$ Graduate School of Natural and Applied Sciences, Ankara University, Ankara, Turkey \\ ${ }^{2}$ Department of Chemistry, Faculty of Science, Ankara University, Ankara, Turkey
}

Abstract: A bentonite sample taken from Reşadiye (Tokat/Turkey) deposit was mixed with distilled water. The formed permanent aqueous suspension was separated by decantation from the flocculated solid fraction. The deflocculated mass percent of the bentonite was evaluated almost $60 \%$ by weighing. The bentonite and its permanently suspended solid fraction are examined by using X-ray diffraction, chemical, thermal, cation exchange, and particle size analyses. Mineralogy and chemical composition of the samples were discussed with respect to the experimental results. A sodium-rich aluminum, iron, and magnesium smectite was determined as the major clay mineral in the bentonite and also illite as minor one. Clinoptilolite, plagioclase, quartz, opal-CT, calcite, magnesite, and dolomite are the nonclay minerals found in the bentonite as impurities. The suspension contains large amount sodium-rich smectite and plagioclase whereas lesser opal-CT. Particle size of the bentonite and deflocculated fraction was found to be lesser than $11 \mu \mathrm{m}$ and $2 \mu \mathrm{m}$, respectively.

Keywords: Bentonite, Cation exchange capacity, Mineralogy, Smectite, Suspension.

Submitted: March 05, 2019. Accepted: October 03, 2019.

Cite this: Özgüven F, Pekdemir A, Önal M, Sarıkaya Y. Characterization of a Bentonite and Its Permanent Aqueous Suspension. JOTCSA. 2020;7(1):11-8.

DOI: https://doi.org/10.18596/jotcsa.535937.

*Corresponding author. E-mail: onal@science.ankara.edu.tr. Tel.: +90 3122126720 / 1173.

Fax: +903122232395.

\section{INTRODUCTION}

Natural sedimentary rocks which contain a smectite to be major clay mineral is called as bentonite. Besides smectites, bentonites also include other clay and nonclay minerals as impurities with the different contents (1). Smectites are the ionic compounds but undissolved in water. Their multiatomic anions are hydrated and hydroxylated aluminum, iron, magnesium or lithium silicates. The corresponding monoatomic cations are $\mathrm{Na}^{+}$or $\mathrm{Ca}^{2+}$ as well as both of them and lesser amount $\mathrm{K}^{+}$. Clay minerals in smectite group were named according to their chemical composition such as montmorillonite, beidellite, nontronite, hectorite, and saponite (2).
Smectite anions formed from layers with the three sheets. Each layer has two silica tetrahedral $(T)$ sheets bonded by oxygen bridges to a central alumina octahedral (O) sheet. Thus, smectites are called 2:1 (TOT) layered clay minerals (3). There are considerable substitution of $\mathrm{Fe}^{2+}, \mathrm{Mg}^{2+}$ and $\mathrm{Li}^{+}$for $\mathrm{Al}^{3+}$ in the dioctahedral sheets and also less substitution of $\mathrm{Al}^{3+}$ for $\mathrm{Si}^{4+}$ in the tetrahedral sheets. Here, to have electrical neutrality, three $\mathrm{Mg}^{2+}$ or $\mathrm{Fe}^{2+}$ are needed instead of two $\mathrm{Al}^{3+}$ or $\mathrm{Fe}^{3+}$. Smectites including more divalent or trivalent cations are distinguished as dioctahedral or trioctahedral.

The TOT (2:1) layers negatively charged depending on these ion exchanges. This negative 
electrical charge is generally balanced by the $\mathrm{Na}^{+}$ and $\mathrm{Ca}^{2+}$ cations diffused between the TOT layers and around their edges. These can be exchangeable with the many inorganic and organic cations. The minerals having $\mathrm{Na}^{+}$and $\mathrm{Ca}^{2+}$ ions as the major exchangeable cations are called sodium-rich smectite (NaS) and calciumrich smectite (CaS), respectively. Generally, NaS has one water layer whereas CaS has two ones in the interlayer. NaS dispersed in water gives permanent suspension whereas CaS gives a temporary one (4-6). Natural rocks having NaS or CaS as major clay minerals are called sodium bentonite $(\mathrm{NaB})$ or calcium bentonite ( $\mathrm{CaB})$, respectively. The equivalent amount of exchangeable cations in unit mass such as one kilogram of smectite or bentonite is defined to be cation exchange capacity (CEC). The high layer charge and cation exchange capacity, high nanoporosity and surface area, fine particle size and also swelling capacity, high viscosity and thixotropy of their aqueous suspension are the excellent physicochemical properties of the smectites as well as bentonites (7-10).

Natural and chemically modified bentonites are used either directly or as an industrial raw materials in a large number areas depending on the physicochemical properties (11-13). Some of the areas directly used are drilling mud, dam filler, foundry sand binder, pat litter, ceramic, crayons, cement, desiccants, and agricultural carriers (14). Some of the modified bentonite and their major clay mineral smectites are used as decolorization earth, catalyst, pillared clay, organoclay, and polymer-clay nanocomposites (15-17). They are also used as an additive to prepare paints, cosmetics, adhesives, emulsion stabilizers, animal feed bonds, and cleaning agents. Pure smectite minerals are rarely found in the nature. Therefore, they would be isolated from bentonites.

The usage area and economic value of bentonites change depending on the type, crystal structure, and physicochemical properties of their smectite as well as other clay and nonclay minerals. Beside smectite other clay minerals are harmless for human health whereas the crystalline silicas such as quartz, cristobalite, and tridymite as well as a zeolite mineral named erionite are harmful (18-20). Fly powder of these minerals of less than $5 \mu \mathrm{m}$ particle size and $0.1 \%$ by mass in a bentonite would cause to an illness called as silicosis. Therefore, the aim of the present study is to characterize the minerals in a bentonite and its permanent aqueous suspensions.

\section{MATERIAL AND METHODS}

A light yellow-colored bentonite sample taken from Reşadiye (Tokat, Turkey) bed was used as the main material in this study. A sample having the mass of $10 \mathrm{~g}$ was weighed from the bentonite powder which is previously dried at $100{ }^{\circ} \mathrm{C}$ for 2 hours. The sample was mixed with $0.5 \mathrm{~L}$ of distilled water in a beaker. The resulting heterogeneous mixture was stirred for one day and then left to stand. After one week, the permanent suspensions was removed by pulling with a pipette. This decantation process was repeated until it does not form any permanent suspension. The consecutive suspensions were accumulated in a beaker and heated until the water was removed. The formation of the permanent aqueous suspension indicated that the separated fraction contain a sodium-rich smectite as the major clay mineral. The BrunauerEmmett- Teller (BET) specific surface area (S), specific nanopore volume (V) and nanopore size distribution of bentonite (BE) and also separated fraction (SF) were determined in an our previous study (21). According to this, $S$ values for $B E$ and SF are 27 and $43 \mathrm{~m}^{2} \mathrm{~g}^{-1}$ as well as $\mathrm{V}$ values 0.055 and $0.065 \mathrm{~cm}^{3} \mathrm{~g}^{-1}$, respectively.

The $X$-ray diffraction (XRD) patterns for the bentonite (BE) and separated fraction (SF) were recorded from random mounts prepared by glass slide method using a Rikagu D-Max 2200 Powder Diffractometer. It operates at $40 \mathrm{kV}$ and $30 \mathrm{~mA}$, using $\mathrm{Ni}$ filtered $\mathrm{CuK}_{\mathrm{a}}$ radiation having 0.15418 $\mathrm{nm}$ wavelength at a scanning speed of $2^{\circ} 2 \theta$ $\min ^{-1}$.

The BE and SF samples were digested in a furnace at $1000{ }^{\circ} \mathrm{C}$ for $2 \mathrm{~h}$ and weighed after cooling to the room temperature. The mass loss by this process was taken as loss on ignition (LOI). Chemical analysis of the samples were performed as the mass percent of metal oxides by using a Hitachi Z-2200 Atomic Absorption Spectrophotometer.

Cation exchange capacity for the BE and SF samples were determined by the methylene blue method (22). Aqueous suspensions of BE and SF were prepared by mixing $2 \mathrm{~g}$ of the sample and $300 \mathrm{~mL}$ of distilled water. The $\mathrm{pH}$ values of these suspensions were adjusted in the interval of 2.5 and 3.8 by using $0.05 \mathrm{M} \mathrm{H}_{2} \mathrm{SO}_{4}$ solution. The prepared suspensions were titrated with $0.01 \mathrm{M}$ aqueous methylene blue solution. The end of the titration was determined by the blue coloration of the suspension on a filter paper.

Thermal gravimetric analysis (TG) and differential thermal analysis (DTA) plots of the BE and SF samples were recorded between 25 and $1400{ }^{\circ} \mathrm{C}$ with the heating rate $10 \mathrm{Kmin}^{-1}$ and $\mathrm{a}-\mathrm{Al}_{2} \mathrm{O}_{3}$ was used as inert material.

Particle size distribution of the BE and SF samples in their aqueous suspensions were 
determined by using a Mastersizer Instrument based on a light scattering technique. The content of the BE and SF samples are 0.0187 and 0.0071 as Vol. \% in the suspensions, respectively.

\section{RESULTS AND DISCUSSION}

\section{Mass fraction of the deflocculated solid}

Mass of the SF was determined to be $6 \mathrm{~g}$ in the permanent aqueous suspension which is formed on the heterogeneous mixture of $10 \mathrm{~g}$ of $\mathrm{BE}$ and $0.5 \mathrm{~L}$ of distilled water. Accordingly, the mass fraction $(X)$ of SF in BE must be:

$$
x=6 \mathrm{~g} / 10 \mathrm{~g}=0.6
$$

Namely, the content of the SF in the BE is $60 \%$ by mass.

\section{XRD- analyses}

XRD pattern of the $\mathrm{BE}$ and SF are respectively given in Figures 1 and 2. Accordingly, major and minor clay minerals in bentonite are a sodiumrich smectite (NaS) and an illite (I), respectively (23). Illites are 2:1 layered minerals as well as smectites but they contain almost unexchangeable $\mathrm{K}^{+}$cations between the layers instead of exchangeable $\mathrm{Na}^{+}$and $\mathrm{Ca}^{2+}$. There are also clay minerals contained mixture of smectite and illite layers in different ratios. Nonclay minerals such as silica, carbonate, feldspar, and zeolite are found in the bentonite in various contents as impurities. Opal-A (OA: $\left.\mathrm{SiO}_{2} \cdot \mathrm{nH}_{2} \mathrm{O}\right)$, opal-CT (OCT: $\left.\mathrm{SiO}_{2} \cdot \mathrm{nH}_{2} \mathrm{O}\right)$, and quartz (Q: $\left.\mathrm{SiO}_{2}\right)$ are the amorphous, paracrystalline and crystalline silica polymorphs, respectively. Calcite $\left(\mathrm{C}: \mathrm{CaCO}_{3}\right)$, magnesite $\left(\mathrm{M}: \mathrm{MgCO}_{3}\right)$, and dolomite $\left(\mathrm{D}: \mathrm{CaCO}_{3} \cdot \mathrm{MgCO}_{3}\right)$ are the carbonate minerals. Clinoptilolite (Cln) is a zeolite that is the nonhydroxylated but hydrated silicate mineral. The chemical formula for the clinoptilolite is given nearly as $(\mathrm{Na}, \mathrm{Ca})_{4-6} \mathrm{Al}_{6}(\mathrm{Al}, \mathrm{Si})_{4} \mathrm{Si}_{29} \mathrm{O}_{72} \cdot 24 \mathrm{H}_{2} \mathrm{O}$. Plagioclase (PO) found in the bentonite is a feldspar that are the non-hydroxylated and nonhydrated silicate mineral. Plagioclase is a mixture of the albite $\left(\mathrm{NaAlSi}_{3} \mathrm{O}_{8}\right)$ and anorthite $\left(\mathrm{CaAlSi}_{2} \mathrm{O}_{8}\right)$ minerals. Its general chemical formula can be given in the following form $\mathrm{Na}_{x} \mathrm{Ca}_{y} \mathrm{Al}_{\mathrm{x}+2 \mathrm{y}} \mathrm{Si}_{3 \mathrm{x}+2 \mathrm{y}} \mathrm{O}_{8}$ where $\mathrm{x}+\mathrm{y}=1$ and $0 \leq \mathrm{y} \leq 1$. Plagioclase is a ceramic flux as well as other feldspars. Although their crystal structures are different the chemical composition of clay, feldspar and zeolite minerals are close to each other.

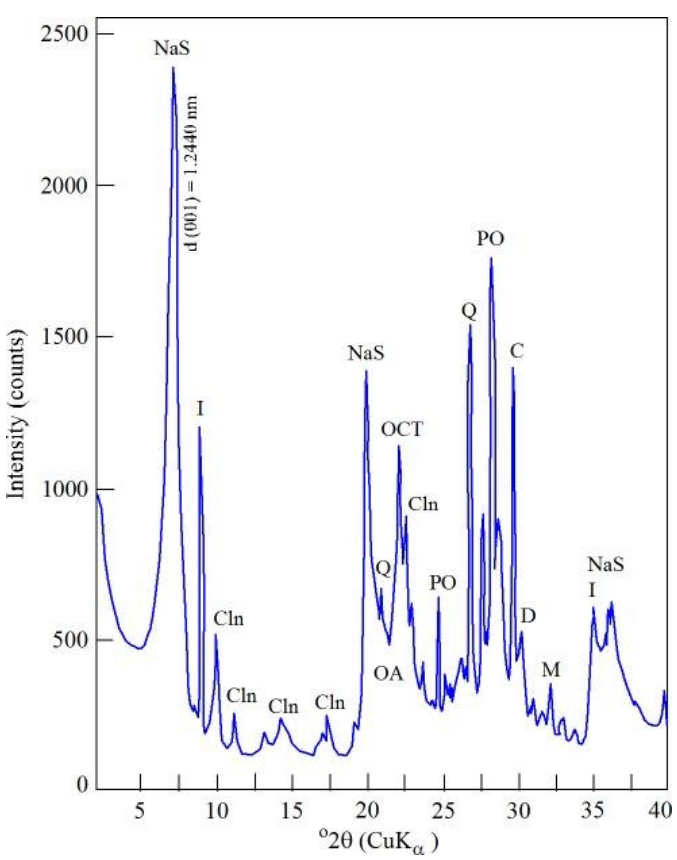

Figure 1. The XRD-pattern for the natural bentonite (NaS: Sodium smectite, I: Illite, Cln: Clinoptilolite, OA: Opal-A, OCT: Opal-CT, Q: Quartz, PO: Plagioclase, C: Calcite, D: Dolomite, M: Magnesite).

The SF contains feldspar and lesser opal-CT as the impurities. Evaluating of the XRD-reflection at $2 \theta=28.2^{\circ}$ indicated that the feldspar is a

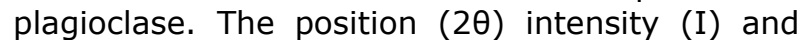
full width at half maximum (FWHM) peak height for the sodium smectite (NaS) and plagioclase (PO) minerals were evaluated and represented on the Figure 2. The type, abundance, and crystallite for a mineral are characterized by the position, intensity and width of the major XRD reflections. 


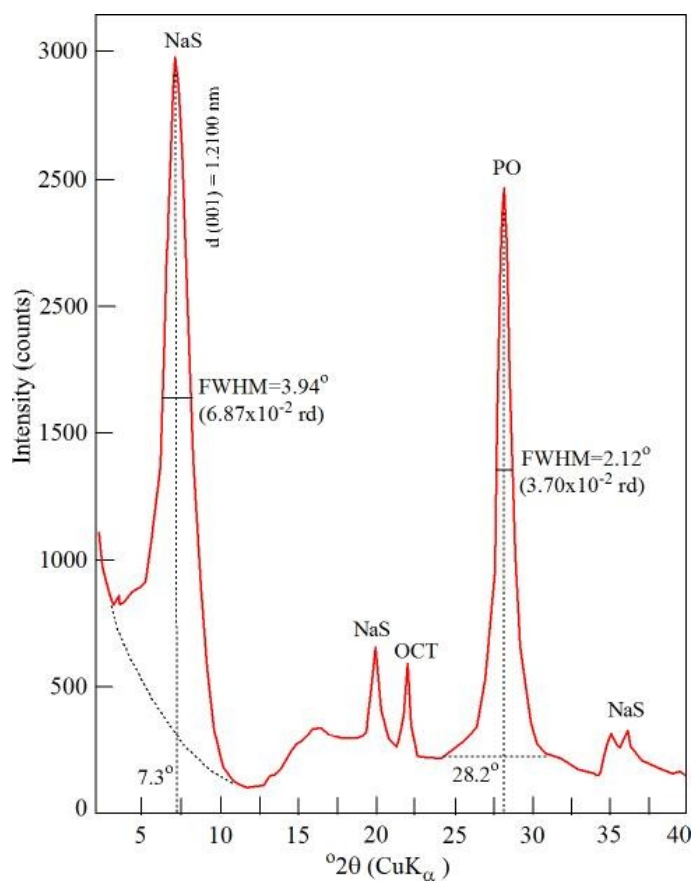

Figure 2. The XRD-pattern for a fraction (SF) of the natural bentonite (BE) that is permanently deflocculated in water (NaS: Sodium smectite, OCT: Opal-CT, PO: Plagioclase)

The XRD reflection at $2 \theta=7.3^{\circ}$ is the most characteristic for sodium-rich smectite (NaS). This peak results from diffraction of X-rays with the wavelength $\lambda=0.15418 \mathrm{~nm}$ reflected by the successive 2:1 (TOT) layer surfaces $(n=1)$.
Accordingly, the total thickness ( $d$ ) of the TOT and a water layers located in the interlayer position is calculated from the Bragg equation in the following form:

$$
d=\frac{n \lambda}{2 \sin \theta}=\frac{1(0.15418 \mathrm{~nm})}{2 \sin (7.3 / 2)^{\circ}}=1.21 \mathrm{~nm}
$$

Ideal value of the of $\mathrm{d}$ for $\mathrm{NaS}$ and CaS is $1.2 \mathrm{~nm}$ and $1.5 \mathrm{~nm}$, respectively. For this reason, the clay minerals permanently separated in water is called sodium-rich smectite.

Full width at half maximum (FWHM) peak height above background for the most characteristic
$\mathrm{XRD}$ reflection of $\mathrm{NaS}$ is evaluated to be $3.94^{\circ}$ $\left(6.87 \times 10^{-2} \mathrm{rd}\right)$ as indicated in Figure 1 . The average size (23) of the smectite crystal in the direction perpendicular to the reflection surfaces is calculated from the Scherrer equation (24) in the following form:

$$
L=\frac{K \lambda}{F W H M \cos \theta}=\frac{10(0.15418 \mathrm{~nm})}{\left(6.87 * 10^{-2} r d\right) \cos \left(\frac{7.3}{2}\right)^{0}}=25.29 \mathrm{~nm}
$$

where $K=10$ is a constant when unit of wavelength is $\mathrm{nm}$.

$$
\begin{gathered}
d=\frac{n \lambda}{2 \sin \theta}=\frac{1(0.15418 \mathrm{~nm})}{2 \sin (28.2 / 2)^{\circ}}=0.32 \mathrm{~nm} \\
L=\frac{K \lambda}{F W H M \cos \theta}=\frac{10(0.15418 \mathrm{~nm})}{\left(3.70 \times 10^{-2} \mathrm{rd}\right) \cos (28.2 / 2)^{\circ}}=42.98 \mathrm{~nm}
\end{gathered}
$$


where $2 \theta$ and FWHM values were taken from Figure 2. These are larger than those of smectite.

\section{Chemical analysis}

Chemical analyses of the BE and SF samples are given in Table 1 as mass percentages of the metal oxides. Since the chemical composition of smectites and other silicate minerals are close to each other there is no great significant change between the chemical analyses. However, the greater percentages of $\mathrm{Al}_{2} \mathrm{O}_{3}, \mathrm{Fe}_{2} \mathrm{O}_{3}$ and $\mathrm{MgO}$ in SF than those of $\mathrm{BE}$ are due to the spontaneous transfer of $\mathrm{NaS}$ and plagioclase into the aqueous suspension. The lesser percentages of $\mathrm{CaO}$ in SF revealed that the calcium-rich smectite, calcite, and dolomite minerals do not spontaneously deflocculated into water. Consequently, clay mineral in the suspension would be a sodium-rich aluminum, iron, and magnesium smectite.

Table 1. Chemical analysis of the bentonite (BE) and its permanently separated fraction (SF) in water.

\begin{tabular}{llllllllll}
\hline Samples & $\mathrm{SiO}_{2}$ & $\mathrm{Al}_{2} \mathrm{O}_{3}$ & $\mathrm{Fe}_{2} \mathrm{O}_{3}$ & $\mathrm{MgO}$ & $\mathrm{TiO}_{2}$ & $\mathrm{CaO}$ & $\mathrm{Na}_{2} \mathrm{O}$ & $\mathrm{K}_{2} \mathrm{O}$ & $\mathrm{IOL}$ \\
\hline BE & 62.60 & 16.65 & 3.44 & 1.63 & 0.29 & 3.37 & 2.59 & 0.98 & 8.45 \\
SF & 61.97 & 19.73 & 4.74 & 2.40 & 0.22 & 0.91 & 2.58 & 0.38 & 7.08 \\
\hline
\end{tabular}

\section{Cation exchange capacity}

The exchangeable cations of smectite minerals can be quantitatively displaced with the methylene blue cations (22). Cation exchange capacity of BE and SF were determined as 65 and $108 \mathrm{meq} / 100 \mathrm{~g}$, respectively. Thus, the mass percent of SF in BE would be as follows:

$$
x=\frac{65 \mathrm{meq} / 100 \mathrm{~g}}{108 \mathrm{meq} / 100 \mathrm{~g}}=0.60
$$

This result revealed that the feldspar mineral found is SF has exchangeable cations such as $\mathrm{Na}^{+}$ and $\mathrm{Ca}^{2+}$ as well as smectites. This value matched to the mass ratio determined by the weighing as the mentioned above.

\section{Thermal analysis}

The TG/DTA patterns for the BE and SF samples are respectively given in Figures 3 and 4 . While the temperature is increasing in the range of 25 and $450{ }^{\circ} \mathrm{C}$, the endothermic mass decreases are caused from the loss of the zeolitic as well as hydration water in the minerals. The endothermic mass decreases in the temperature interval of 450 and $750{ }^{\circ} \mathrm{C}$ are only due to the dehydroxylation of clay minerals. The mass loss for the BE and SF samples is evaluated from the TG curves as $5.3 \%$ and $4.4 \%$, respectively. The exothermic peaks located between 900 and 1000 ${ }^{\circ} \mathrm{C}$ are due to the decomposition of the silicate minerals in the bentonite which are mentioned above. The endothermic peaks at almost $1200^{\circ} \mathrm{C}$ are caused from the melting of the plagioclase which is a fluxing material for ceramic industry.

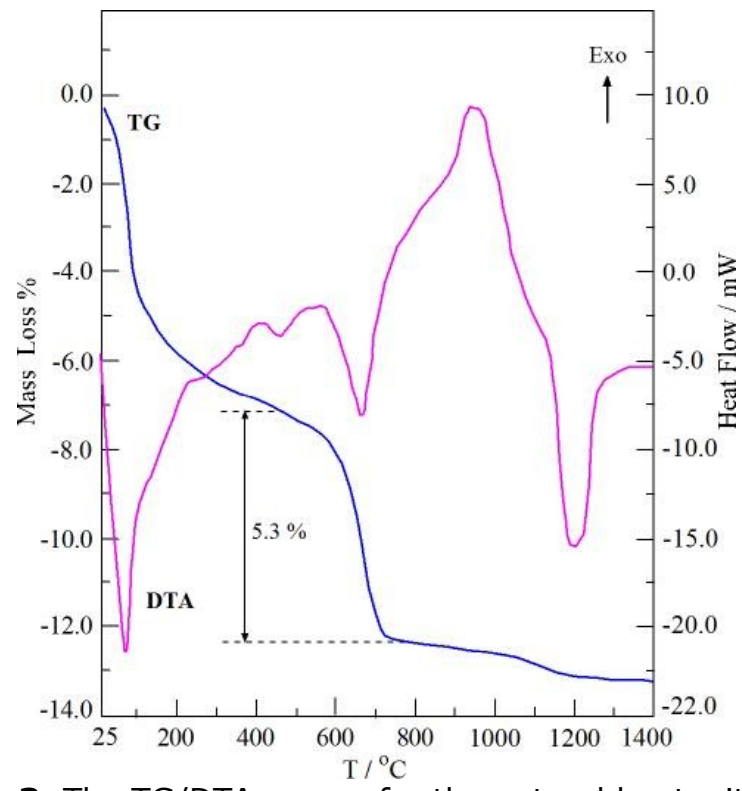

Figure 3. The TG/DTA curves for the natural bentonite (BE). 


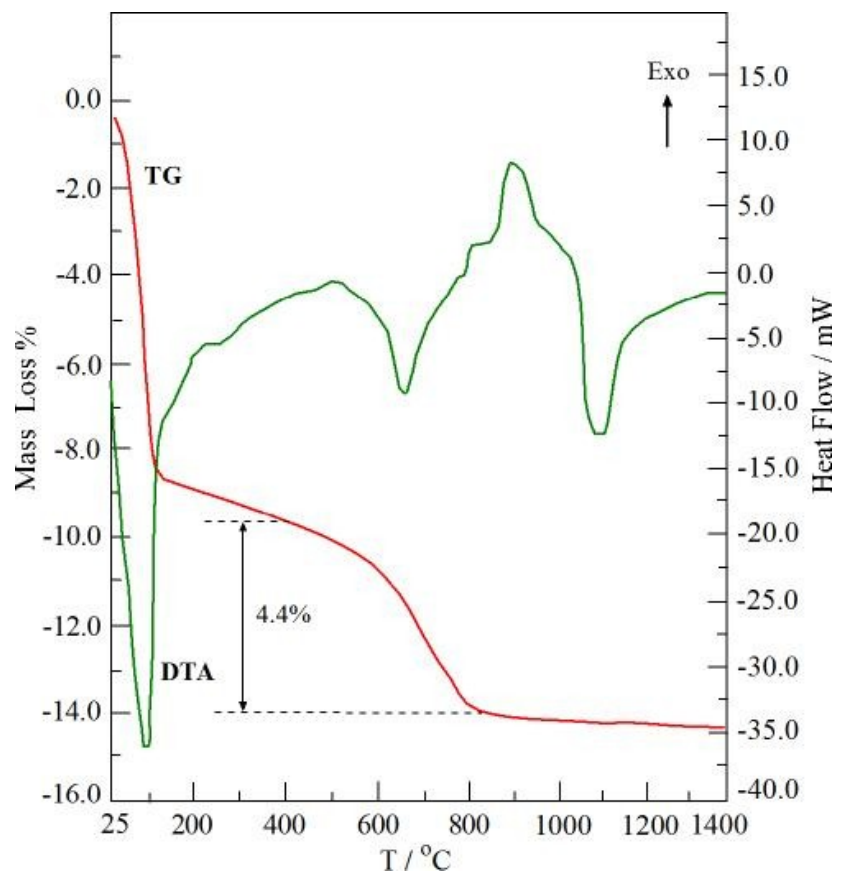

Figure 4. The TG/DTA curves for a fraction (SF) of the natural bentonite (BE) that is permanently deflocculated in water.

\section{Particle size distribution}

The particle size distribution curves of the BE and SF sample are given in Figures 5 and 6. Two peaks laying on the size interval lesser than $2 \mu \mathrm{m}$ would be caused from the smectite and plagioclase which are spontaneously deflocculated in water. This result also showed that the particle size of quartz is larger than 2 $\mu \mathrm{m}$. The third peak in Figure 5 is originated from other clay and nonclay particles that are spontaneously flocculated fraction of the bentonite in a short time. Thus, the volume percent of the deflocculated particles was read from the cumulative particle size curve to be 0.60 as represented in Figure 5 . This value is completely match with the mass percent found above. This equality revealed that the mean density of the BE and SF is almost equal each other.

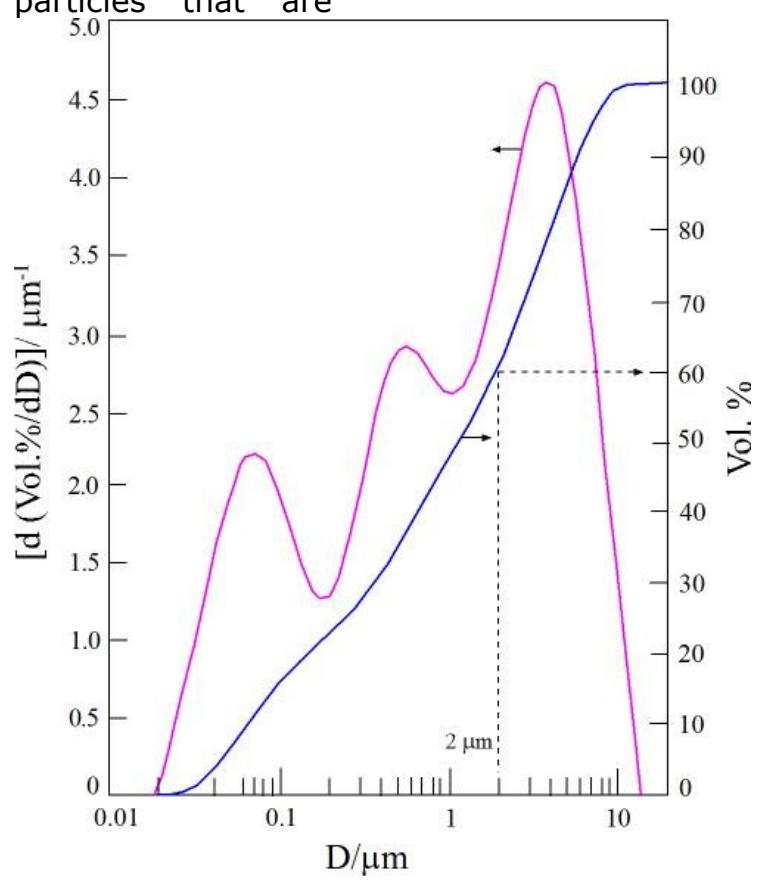

Figure 5. The cumulative and differential particle size distribution curves of the natural bentonite (BE). 


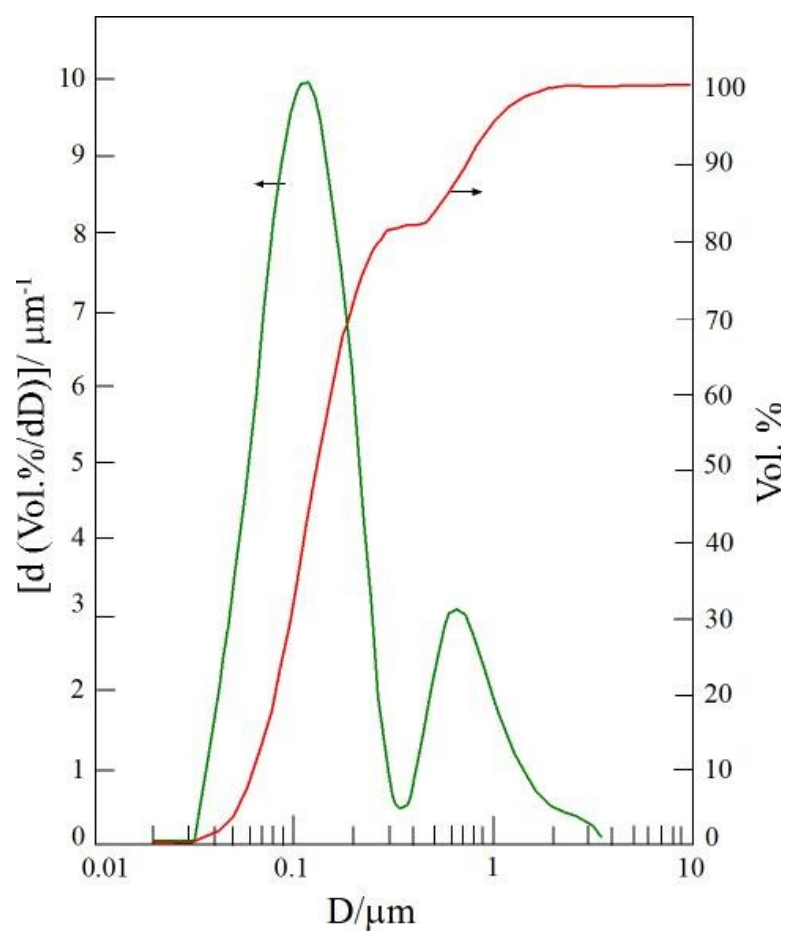

Figure 6. The cumulative and differential particle size distribution curves for a fraction (SF) of the natural bentonite (BE) that is permanently deflocculated in water.

\section{CONCLUSION}

The microsized particles of minerals formed from the agglomeration of their nanosized crystals. A bentonite and its fraction which is permanently deflocculated in water would be extensively investigated to obtain using areas and economic value. Mineralogy, chemical composition, and several physicochemical properties such as cation exchange capacity, thermal behavior, and particle size distribution of the samples should be discussed according to the possible uses. The evidence of the minerals such as quartz, cristobalite, tridymite, and erionite which are harmful for human health are ought to preciously investigated. For example, there is quartz in the examined bentonite with the particle size larger than $2 \mu \mathrm{m}$, but it is not permanently deflocculated in water. So, this harmless fraction may be used to prepare organoclays, pillared clays, electrodes, and clay-polymer nanocomposites. On the other hand; drilling mud, foundry sand binder, and dam filler preparation are seen the possible uses areas of the natural bentonite. Because of the bentonite contain harmful quartz the workers must use dust masks.

\section{ACKNOWLEDGMENTS}

The authors thank to Research Foundation of Ankara University (Project No:17H0430010) for financial support to this work.

\section{REFERENCES}

1. Grim RE. The history of the development of clay mineralogy. Clays and Clay Minerals. 1988;36:97-101

2. Grim RE, Güven N. Bentonites- Geology, Mineralogy, Properties and Uses. Developments in Sedimentology, 24. Elsevier; New York, 1978.

3. Grim RE. Clay Mineralogy, McGraw-Hill; New York, 1968.

4. Bergman WE and Fisher HB. Bentonite suspensions. Industrial and Engineering Chemistry. 1950;42:1895-1900.

5. Luckham PL, Rossi S. The colloidal and rheological properties of bentonite suspensions. Advanced in Colloid and Interface Science. $1999 ; 82: 43-92$.

6. Minase $M$, Kondo $M$, Onikato $M$, Kawamura $K$. The viscosity of suspensions of bentonite. Clay Science. 2006;12:125-130.

7. Rollins MB. Sealing properties of bentonite suspensions, Clays and Clay Minerals. $1969 ; 16: 415-423$.

8. Zhu R, Chen Q, Zhou Q, Xi Y, Zhu J, He H. Adsorbates based on montmorillonite for contaminant removal from water: a review. Applied Clay Science.2016;123: 239-258. 
9. Uddin MK. A review on the adsorption of heavy metals by clay minerals, with special focus on the past decade. Chemical Engineering Journal.2017;308:438-462.

10. Derakhshany E, Naghizadeh A. Optimization of humic acid removal by adsorption onto bentonite and montmorillonite nanoparticles. Journal of Molecular Liquids. 2018;259:76-81.

11. Noyan $H$, Önal M, Sarıkaya $Y$. The effect of heating on the surface area, porosity and surface acidity of a bentonite. Clay and Clay Minerals. 2006;54:375-381.

12. Noyan $H$, Önal M, Sarıkaya $Y$. The effect of sulphuric acid activation on the crystallinity, surface acidity, and bleaching power of a bentonite. Food Chemistry. 2007;105:156-163.

13. Komadel P. Acid activated clays: Materials in continuous demand. Applied Clay Science. 2016;131:84-99.

14. Murray HH. Traditional and new applications for kaolin, smectite, and palygorskite: a general overview. Applied Clay Science. 2000;17:207221.

15. Çelik M, Önal M. Synthesis and characterization of poly(glycidyl methacrylate)/Na-montmorillonite

nanocomposites. Journal of Applied Polymer Science. 2004;94:1532-1538.

16. Çelik M, Önal M. Polymethacrylamide/Namontmorillonite nanocomposites synthesized by free-radical polymerization. Material Letters. 2006;60:48-52.
17. Silva $S M$, Sampaio KA, Ceriani $R$, Verhe $R$, Stevens C, De Greyt W, Meirelles JA. Effect of type of bleaching earth on the final color of refined palm oil. LTW-Food Science and Technology. 2014;59:1258-1264.

18. Elzea JM, Odom IE, Miles WJ. Distinguishing well ordered opal-CT and opal-C from high temperature cristobalite by X-ray diffraction. Analytica Chimica Acta. 1994;286:107-116.

19. Elzea JM, Rice SB. TEM and X-ray diffraction evidence for cristobalite and tridymite stacking sequences in opal. Clays and Clay Minerals. 1996;44:492-500.

20. Önal $M$, Kahraman $S$, Sarıkaya $Y$. Differentiation of a- cristobalite from opals in bentonites from Turkey. Applied Clay Science. 2007;35:25-30.

21. Önal $M$, Sarıkaya $Y$, Alemdaroğlu $T$, Bozdoğan İ. Isolation and characterization of a smectite as a micro-mesoporous material from a bentonite. Turkish Journal of Chemistry. 2003;27:683-693.

22. Yener N, Biçer C, Önal M, Sarıkaya Y. Simultaneous determination of cation exchange capacity and surface area of acid activated bentonite powders by methylene blue sorption. Applied Surface Science. 2012;258: 2534-2539.

23. Moore DM, Reynolds, Jr RC. X-ray diffraction and the Identification and Analysis of Clay Minerals. Oxford University Press; Oxford, 1997.

24. Patterson A.The Scherrer formula for X-ray particle size determination. Physical Review. 1939;56:978-982. 